\title{
Paediatric vascular imaging: Diagnosis
}

\section{S K Misser, MB ChB, FCRad (D) SA}

Lake Smit and Partners, Durban

\section{J N Narsai, MB ChB, FC Paed SA}

Crompton Hospital, Durban

Corresponding author: S Misser (misser@lakesmit.co.za)

Please refer to page 151 of the December 2011 issue of the SAJR (http://www.sajr.org.za/index.php/sajr/article/view/662/477) for the presentation details. No precise diagnosis was received from the readership. Dr Misser elaborates below on the condition and its imaging.

\section{Presentation and diagnosis}

(Due to space constraints, the images referred to below are not all reproduced here, but are in the online December 2011 SAJR at the above URL.)

The computed tomography angiogram (CTA) confirms presence of a vascular ring (Fig. 1) compressing the trachea at the level of the thoracic inlet. On the volume-rendered reformatted images, the ring conforms to a double aortic arch with stenosis of the right aortic arch component. This may be due to an atretic segment or coarctation and is unusual for this aortic morphology. There is post-stenotic aneurysmal dilatation of the left arch component at the origin of the left subclavian artery, suppposedly an aortic diverticulum (also unusual for double aortic arch). A small aneurysm is also noted from the right aortic arch component just distal to the origin of the right carotid artery. The compressive effect on the trachea is welldemonstrated on the 3-D maximum intensity projection (MIP) virtual bronchoscopy image with remarkable attenuation of the lumen over a long segment, up to just above the carina. The abdominal aorta shown on the abdominal CTA coronal image is of very small calibre. This is probably due to an underlying vasculopathy. Agenesis of the left kidney is also noted incidentally; this should raise suspicion for

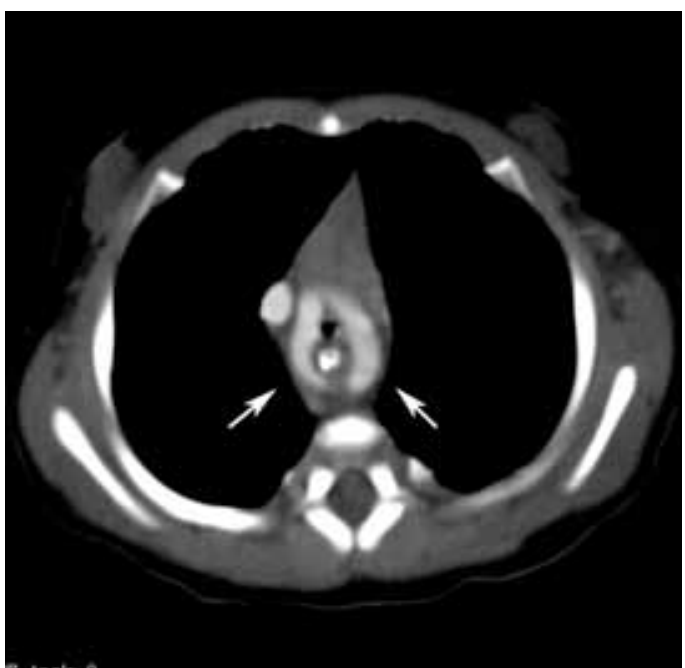

Fig. 1. Note the vascular ring (arrowed).

associations of the VATER syndrome, which are known to occur with double aortic arch anomaly.

\section{Discussion}

The radiological approach to neonatal stridor is broadly based on vascular or non-vascular aetiology. Vascular tracheo-bronchial compression may result from anomalies such as double aortic arch, anomalous left pulmonary artery or aberrant subclavian artery, among

Table 1. Features of complete vascular rings especially with right arch present

\begin{tabular}{|c|c|c|c|}
\hline Vascular anomaly & Embryology & Oesophagography & Other findings \\
\hline Double aortic arch & $\begin{array}{l}\text { Persistence of } 4 \text { th branchial } \\
\text { arches on both sides }\end{array}$ & $\begin{array}{l}\text { Bilateral impressions } \\
\text { on sides of oesophagus } \\
\text { on frontal and posterior } \\
\text { impression on lateral view }\end{array}$ & $\begin{array}{l}\text { Most common vascular ring anomaly. Rarely } \\
\text { associated with cardiac defects }\end{array}$ \\
\hline $\begin{array}{l}\text { Right aortic arch with aberrant } \\
\text { origin of left subclavian artery, } \\
\text { with ligamentum arteriosum } \\
\text { and aortic diverticulum }\end{array}$ & $\begin{array}{l}\text { Interruption of left aortic } \\
\text { arch between left carotid } \\
\text { and subclavian arteries }\end{array}$ & $\begin{array}{l}\text { Posterior impression on } \\
\text { trachea and barium-filled } \\
\text { oesophagus }\end{array}$ & $\begin{array}{l}\text { Heart normal in size } \\
\text { Aorta descends on right } \\
\text { Associated cardiac defects in } 5-10 \% \text { esp. tetralogy, } \\
\text { ASD, VSD, coarctation }\end{array}$ \\
\hline $\begin{array}{l}\text { Right aortic arch with mirror } \\
\text { image branching }\end{array}$ & $\begin{array}{l}\text { Symmetrical great vessel } \\
\text { branching pattern }\end{array}$ & $\begin{array}{l}\text { No posterior impression } \\
\text { on trachea or barium-filled } \\
\text { oesophagus }\end{array}$ & $\begin{array}{l}\text { Heart is abnormal in size/shape owing to associated } \\
\text { congenital cardiac defect }(>95 \%) \text { esp. tetralogy, } \\
\text { ASD, VSD, coarctation. } \\
\text { Aorta descends on right }\end{array}$ \\
\hline $\begin{array}{l}\text { Right aortic arch with aberrant } \\
\text { left innominate artery }\end{array}$ & $\begin{array}{l}\text { Aberrant innominate artery } \\
\text { may arise from diverticulum }\end{array}$ & $\begin{array}{l}\text { Posterior compression } \\
\text { defect on the barium-filled } \\
\text { oesophagus }\end{array}$ & $\begin{array}{l}\text { Rare vascular ring with right arch. Not usually } \\
\text { associated with other cardiac defects }\end{array}$ \\
\hline
\end{tabular}


others. Clinically, hyperextension of the neck is usually observed as this position affords some relief. Stridor resulting from tracheal compression is often aggravated by feeding. The diagnosis is usually suggested by this neonatal clinical presentation.

The first description of a vascular ring (a double aortic arch) was by Hommel in 1737. Vascular rings result from the abnormal or incomplete regression of one of the 6 embryonic branchial arches. Contrast swallow studies have been used to classify the vascular causes of tracheal compression based on the indentations on the oesophagus. Baker and Berdon ${ }^{1}$ reviewed Klinkhamer's ${ }^{2} 20$ patterns and formulated 4 typical patterns on oesophagography (Table 1). Contrast studies may, however, not be possible in some instances where the child is intubated and ventilated.

Current trends in CT evolution and magnetic resonance angiography (MRA) have made a multimodality imaging approach possible in the assessment and treatment of these complex vascular anomalies. MRA has the added benefit of no ionising radiation, which is useful in children where follow-up studies are usually necessary.
Conventional digital subtraction angiography (DSA), although diagnostic in its demonstration of the vascular anomalies, has largely been replaced by CTA and MRA. Schlesinger et al. ${ }^{3}$ described imaging appearances of 10 patients with similar arch anomaly to that presented in this quiz case. It is a rare variant, and it is imperative for the radiologist to identify the vascular abnormality and describe the ring in detail, as the surgical approach is highly dependent on the imaging. In addition, such complex vascular anomalies must be managed at an institution where multislice CT, MRI and high-level paediatric surgical service are available.

1. Berdon WE. Rings, slings, and other things: Vascular compression of the infant trachea. Updated from the midcentury to the millennium - the legacy of Robert E. Gross and Edward B. D. Neuhauser. Radiology 2000;216:624-632.

2. Klinkhamer AC. Esophagography in Anomalies of the Aortic Arch System. Baltimore, MD: Williams \& Wilkins, 1969.

3. Schlesinger AE, Krishnamurthy R, Sena LM, et al. Incomplete double aortic arch with atresia of the distal left arch: Distinctive imaging appearance. AJR 2005;184:1634-1639.

4. Shuford WH, Sybers RG, Edwards FK. The three types of right aortic arch. AJR 1970;109:67-74.

5. Banka P, Geva T, Powell AJ, Geggel R, Lahiri T, Valente AM. Right aortic arch with aberrant left innominate artery. A rare vascular ring. Circulation 2009;120:264-265.

\section{Musculoskeletal imaging of a painful knee}

\section{S K Misser, MB ChB, FCRad (D) SA}

Lake Smit and Partners, Durban

Corresponding author: S Misser (misser@lakesmit.co.za)

\section{Presentation}

A middle-aged woman presented with acute-on-chronic right knee pain. Fig. 1 is a plain radiograph of the right knee 3 weeks before admission. Fig. 2 is a plain radiograph of the right knee on admission. Fig. 3 is a sagittal proton density (PD) fat-saturated image of the right knee. Fig. 4 is a coronal T2-weighted fat-saturated image of the right knee. Fig. 5 is an axial PD fatsaturated image of the right knee. Fig. 6 is a coronal PD fat-saturated image of the right knee.

Describe the relevant findings and provide the most appropriate clinical diagnosis. Please submit your response to Dr Misser at misser@lakesmit.co.za not later than 1 April 2012. The winning respondent will receive a R1 000 award from the RSSA. A detailed diagnosis and discussion will be presented in the next issue of the SAJR.
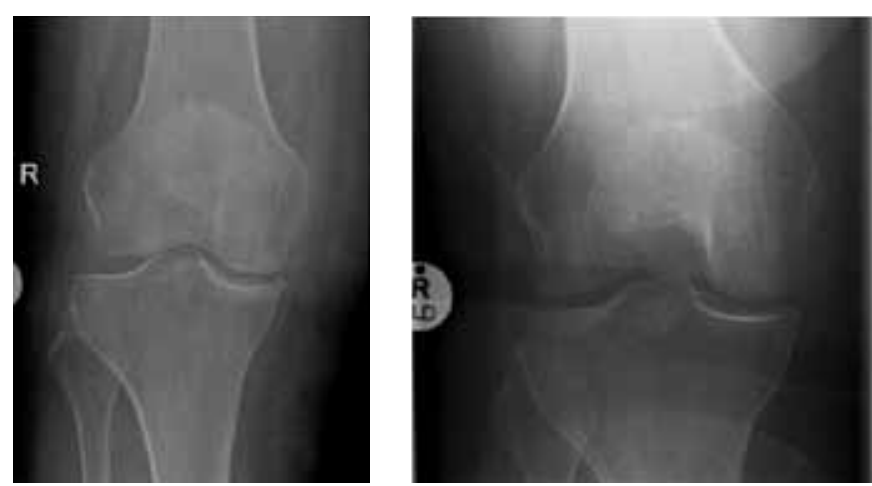

Fig. 1.

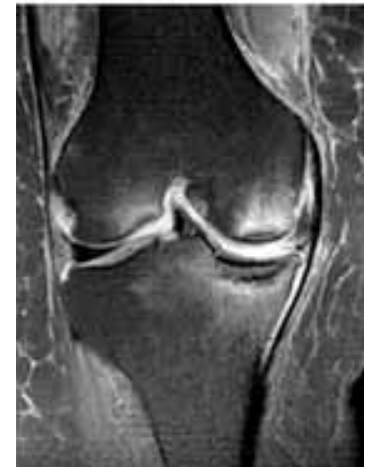

Fig. 4.
Fig. 2.

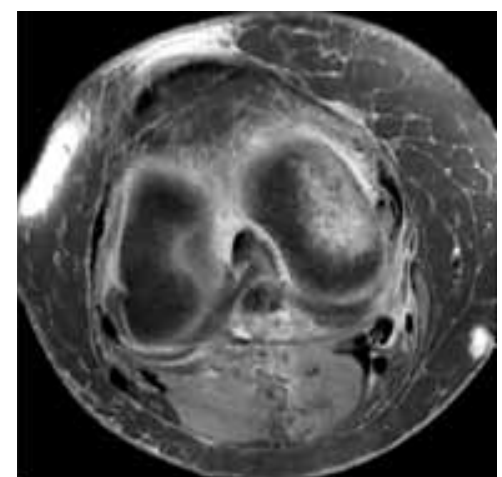

Fig. 5.

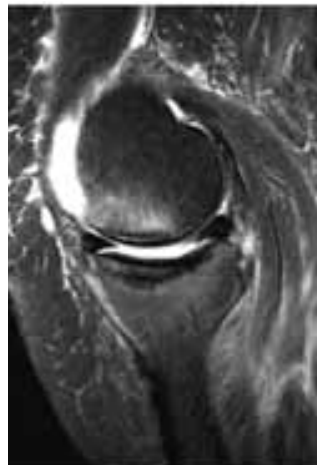

Fig. 3.

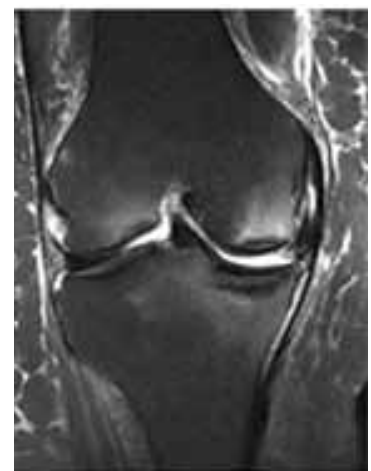

Fig. 6. 